\title{
Longevity of Polish male Olympic medallists born between 1888 and 1965
}

\author{
Łukasz A. Małek ${ }^{1}$, Witold Śmigielski ${ }^{2}$, Hubert Krysztofiak ${ }^{3,4}$, Mikołaj Marszałek $^{5}$, \\ Wojciech Drygas ${ }^{1,6}$
}

1 Department of Epidemiology, Cardiovascular Disease Prevention and Health Promotion, National Institute of Cardiology, Warsaw, Poland; ${ }^{2}$ Department of Demography, University of kódź, kódź, Poland, ${ }^{3}$ Mossakowski Medical Research Centre, Polish Academy of Sciences, Warsaw, Poland; 4 National Centre for Sports Medicine, Warsaw, Poland; ${ }^{5}$ MD student at the Medical University of Warsaw - English Division; ${ }^{6}$ Department of Preventive and Social Medicine, Medical University of Łódź, Łódź, Poland

\begin{abstract}
Study aim: The aim of the study was to analyse the lifespan of Polish male Olympic medallists in comparison to the general male population.

Material and methods: The study included 238 Polish male Olympic medallists who participated in the Olympic games in 1924-1992. Duration of life in relation to the general Polish population was assessed. The age of acquiring their first medal, type and number of medals won and sports discipline were taken into consideration.

Results: Polish male Olympic medallists born before 1940 lived over 8 years longer in comparison to the general population $(\mathrm{p}<0.0001, \mathrm{~d}=0.689$ and $\mathrm{d}=0.750)$. Over $80 \%$ of them lived up to 65 years of age and over $40 \%$ up to 80 . In the general population only $<70 \%$ and $<30 \%$, respectively, reached the equivalent lifespan $(\mathrm{p}=0.010$ and $\mathrm{p}=0.040, \mathrm{RR}=0.480$ and $\mathrm{RR}=0.783)$. Kaplan-Meier analysis demonstrated that survival was shorter in Olympic medallists who won their first medal before the age of $25(\mathrm{p}=0.040)$ and in those engaging in endurance or power sports vs. mixed or skill disciplines $(\mathrm{p}=0.010)$. Conclusions: Polish male Olympic medallists lived significantly longer than the general population of Polish men. The longevity of male Olympic medallists was affected by the age of acquiring their first medal and by the category of sport practised.
\end{abstract}

Key words: Longevity - Mortality - Athlete - Elite - Olympic medallists

\section{Introduction}

Regular physical activity is a factor extensively studied in the prospect of longevity [28]. Profuse research supports the positive impact of even a minimum quantity of exercise on the risk of death, including prevention of cardiovascular diseases, cancer, mental disorders, osteoporosis, and overall better senescence [29]. However, controversies remain with regard to the risk-benefit ratio at the extremes of training $[23,24]$. Current dogma states that there is a curvilinear relation between the amount of exercise and associated health benefits with the plateau observed far into the extremes [7]. An alternative hypothesis suggests the existence of a U-shape pattern with no benefit or harm observed with a very intensive life-long burden of exercise [7]. Arguments in favour of the J-shape hypothesis include data from large population studies with a long-term prospective follow-up showing that the most active cohorts had the lowest mortality with no visible threshold between benefit and risk even at the extremes of exercise $[4,21]$ Contrary to the aforementioned findings stand markers of cardiovascular risk, which are frequently observed in elite athletes. In particular, these include the higher prevalence of atrial fibrillation and calcified atherosclerotic plaques $[8,17,22]$ as well as myocardial fibrosis visible on cardiac magnetic resonance [19]. Additionally, bouts of intensive exercise were related to transient increase of inflammatory markers or to transient myocardial injury assessed with imaging studies and troponin or natriuretic peptides $[10,20,26,27]$. As of today, the riskbenefit discussion is still open.

Olympic medallists constitute an excellent representative sample of the fittest individuals. Studies from countries 
other than Poland showed that despite a high training load and competition related stress Olympic medallists lived 3 to 6 years longer than the general population $[2,3,11]$. Higher longevity occurred despite often co-existing, but hidden cardiovascular risk factors or diseases $[5,25]$. However, differences in benefit related to the type of sport, playing position and demographic or socio-economic factors were noted [25]. Moreover, elite athletes had a lower mortality risk from virtually all causes other than external factors. This finding could possibly be attributed to a higher percentage of risky behaviours and suicides [9].

Thorough analysis of factors affecting longevity of elite athletes could elucidate the mounting evidence behind their prolonged survival. Investigation of the Polish cohort should also allow for a comparison with findings from other parts of the world. Therefore, the aim of the study was to analyse the lifespan of Polish male Olympic medallists in comparison to the general male population. We hypothesized that, as in other parts of the world, also in Poland, Olympic medallists may live longer than the general population despite involvement in strenuous training and competition regimes for many years throughout their careers $[2,3,11]$.

\section{Material and methods}

\section{Study group}

We used a publicly available database of the Polish Olympic Committee (https://www.olimpijski.pl/pl/28, biografie. $\mathrm{html}$ ) to extract the list of Polish Olympic medallists. 406 athletes (Caucasian) were found, of whom 331 were male.

To better analyse the duration of life we divided athletes into 3 cohorts as follows: born before 1920, born within 1921-1940, and born within 1941-1950. This allowed us to focus on the complete observation of life duration (for the first cohort) and observations limited to at least the mean duration of life in the male general population of Poland in the other cohorts. This limited the analysis to 164 subjects. Additionally, 9 more subjects were excluded from the further analysis due to dying during the period of the $2^{\text {nd }}$ World War (1939-1945). Therefore, the final group consisted of 155 athletes. All were medallists from the Olympic games which took place between 1924 and 1972.

An additional cohort of Olympic medallists born between 1951 and 1965, consisting of 83 athletes, was added for the purpose of survival analysis. It included medallists from Olympic games that took place between 1972 and 1992.

\section{Methods}

The date of birth and lifespan and/or time and cause of death of analysed subjects were extracted from the official webpage of the Polish Olympic Committee until October 2019. Verification of the obtained data was based on publicly available online database search. In the case of publicly renowned athletes, this source should be assumed to be reliable.

Additionally, we gathered data on the following parameters: the type of best medal won (gold, silver, or bronze), the age of acquiring the first medal, the total number of Olympic medals won and the character of the sport. Disciplines were divided into individual or team sports and categorized based on their character, that is into: endurance, mixed, power and skill sports, according to the current classification [25]. A young age of winning a medal was established as 25 years or below.

Data regarding the mean survival of the general population onward from the mean age of medal winning in the respective cohorts and the prevalent causes of deaths according to the ICD-10 classification were obtained from the life expectancy tables for Poland from 1950 to 2019 published by the Central Statistical Office.

\section{Statistical analysis}

Categorical data are presented as numbers and percentages and quantitative data are shown as means and standard deviations or medians and interquartile ranges depending on the normality of distribution assessed via the Shapiro-Wilk test. Depending on the sample size, Fisher's exact or chi-square test was used to compare frequencies of deaths before the age of 45 as well as survival to 65 or 80 years of age and to compare causes of death between the examined cohorts and the Polish male population of the era. The Cohen's d value was calculated in the case of lifespan characteristics and RR in the case of proportion values. Student's t-test for independent samples was computed to compare the lifespan between the studied groups. Survival analysis was performed using the Kaplan-Meier curves. All statistical calculations were performed using the STATISTICA 12 software (StatSoft Inc, Tulsa, OK, USA). The significance level was set at $\mathrm{p}<0.05$.

\section{Results}

Baseline characteristics of the studied cohorts are presented in Table 1.

As presented in Table 2, Polish male Olympic medallists born before 1940 lived over 8 years longer in comparison to the general population $(\mathrm{p}<0.0001, \mathrm{~d}=0.689$ and $\mathrm{d}=0.750$ ). Over $80 \%$ lived up to 65 years of age and over $40 \%$ up to 80 . In the general population only $<70 \%$ and $<30 \%$, respectively, reached an equivalent lifespan $(\mathrm{p}=0.010$ and $\mathrm{p}=0.040, \mathrm{RR}=0.480$ and $\mathrm{RR}=0.783$ respectively). No significant difference in life duration was found between the Olympic medallists from the two 
Table 1. Baseline characteristics of the studied group of Polish male Olympic medalists

\begin{tabular}{lccccc}
\hline Parameter & Cohort 1 & Cohort 2 & Cohort 3 & Cohort 4 & All \\
\hline Date of birth & $<1920$ & $1921-1940$ & $1941-1950$ & $1951-1965$ & $<1920-1965$ \\
\hline $\mathrm{N}$ & 25 & 53 & 77 & 83 & 238 \\
Deceased [\%] & $25(100)$ & $37(70)$ & $21(27)$ & $7(8)$ & $90(38)$ \\
Mean age at medal winning, years $\pm \mathrm{SD}$ & $25.2 \pm 6.1$ & $25.7 \pm 6.8$ & $25.6 \pm 6.7$ & $24.7 \pm 6.0$ & $25.3 \pm 6.4$ \\
$<25$ years at medal winning [\%] & $6(24)$ & $13(24)$ & $20(26)$ & $41(49)$ & $80(34)$ \\
\hline Type of the medal [\%] & & & & & \\
$\quad$ Gold & $0(0)$ & $15(28)$ & $32(42)$ & $16(19)$ & $63(26)$ \\
$\quad$ Silver & $9(36)$ & $18(34)$ & $20(26)$ & $35(42)$ & $82(34)$ \\
$\quad$ Bronze & $16(64)$ & $20(38)$ & $25(32)$ & $32(39)$ & $93(40)$ \\
\hline Number of medals [\%] & & & & & \\
$\quad$ 1 & $21(84)$ & $34(64)$ & $64(82)$ & $68(82)$ & $187(79)$ \\
$\quad>1$ & $4(16)$ & $19(36)$ & $13(18)$ & $15(18)$ & $51(21)$ \\
\hline Sport category [\%] & & & & & \\
$\quad$ Endurance & $13(52)$ & $7(13)$ & $9(12)$ & $17(20)$ & $46(19)$ \\
$\quad$ Power & $0(0)$ & $28(53)$ & $20(26)$ & $31(37)$ & $79(33)$ \\
$\quad$ Mixed & $5(20)$ & $15(28)$ & $44(57)$ & $32(39)$ & $96(40)$ \\
$\quad$ Skill & $7(28)$ & $3(6)$ & $4(5)$ & $3(4)$ & $17(7)$ \\
\hline Type of sport [\%] & & & & & \\
$\quad$ Individual & $25(100)$ & $53(100)$ & $42(55)$ & $65(78)$ & $185(78)$ \\
$\quad$ Team & $0(0)$ & $0(0)$ & $35(45)$ & $18(22)$ & $53(22)$ \\
\hline
\end{tabular}

oldest cohorts. A similar pattern of prolonged longevity was evident in the youngest, third cohort, where the complete lifespan could not be analysed for the whole group. Survivability until 65 years of age was similar to the two older cohorts $(p=0.010$ and $p=0.020, R R=0.294$ and $\mathrm{R}=0.479$ respectively). Despite the numerical difference in favour of the Olympic medallists, there was no statistically significant difference in terms of death before 45 years of age in comparison to the general population due to the low number of events.

Cause of death could be identified in 46 of the 90 deceased subjects $(51 \%)$. Comparison to the general population yielded numerical, but not statistical, differences of lower cardiovascular mortality and higher mortality due to external causes (Table 3).

Kaplan-Meier analysis demonstrated that survival was shorter in the Olympic medallists who won a medal at a young age $(p=0.040)$, while in case of differences between various sport categories there was a trend towards significance ( $p=0.090)$, as demonstrated in Figure 1AB. When sports categories were grouped into pure endurance and power sports vs. mixed and skill sports, this difference was significant, favouring mixed and skill sports $(p=0.01)$. The proportion of young medallists in pure endurance/power sports did not differ significantly from the whole studied group $(50 \%$ vs. $52 \%, \mathrm{p}=0.75)$.
No survival discrepancy was noted between Olympic medallists who won one or multiple medals $(p=0.60)$, a gold medal versus a silver or bronze medal $(p=0.63)$, or between individual and team sports $(\mathrm{p}=0.84)$.

\section{Discussion}

For the first time we have calculated the net number of years of life gained by the group of Polish male Olympic medallists in comparison to the general population of men in Poland.

Our noted longevity prolongation among Polish male Olympic medallists is higher than in other large study focused solely on Olympic medallists, which demonstrated 2.8 years longer life in comparison to controls [3]. Our number is closer to the French study, which included more than just medallists, that is all the participants of the Olympic games. It demonstrated an average 6.5 years saved [1]. Our result agrees with the findings of a prospective study on the US population showing that the most active cohorts of men demonstrated a 7 to 8 year gain of life expectancy [18]. Therefore, contrary to the hypothesis that top elite athletes may pay a price for their wins in terms of shorter longevity, we found that in fact the net gain of years of life is similar to studied groups of the 


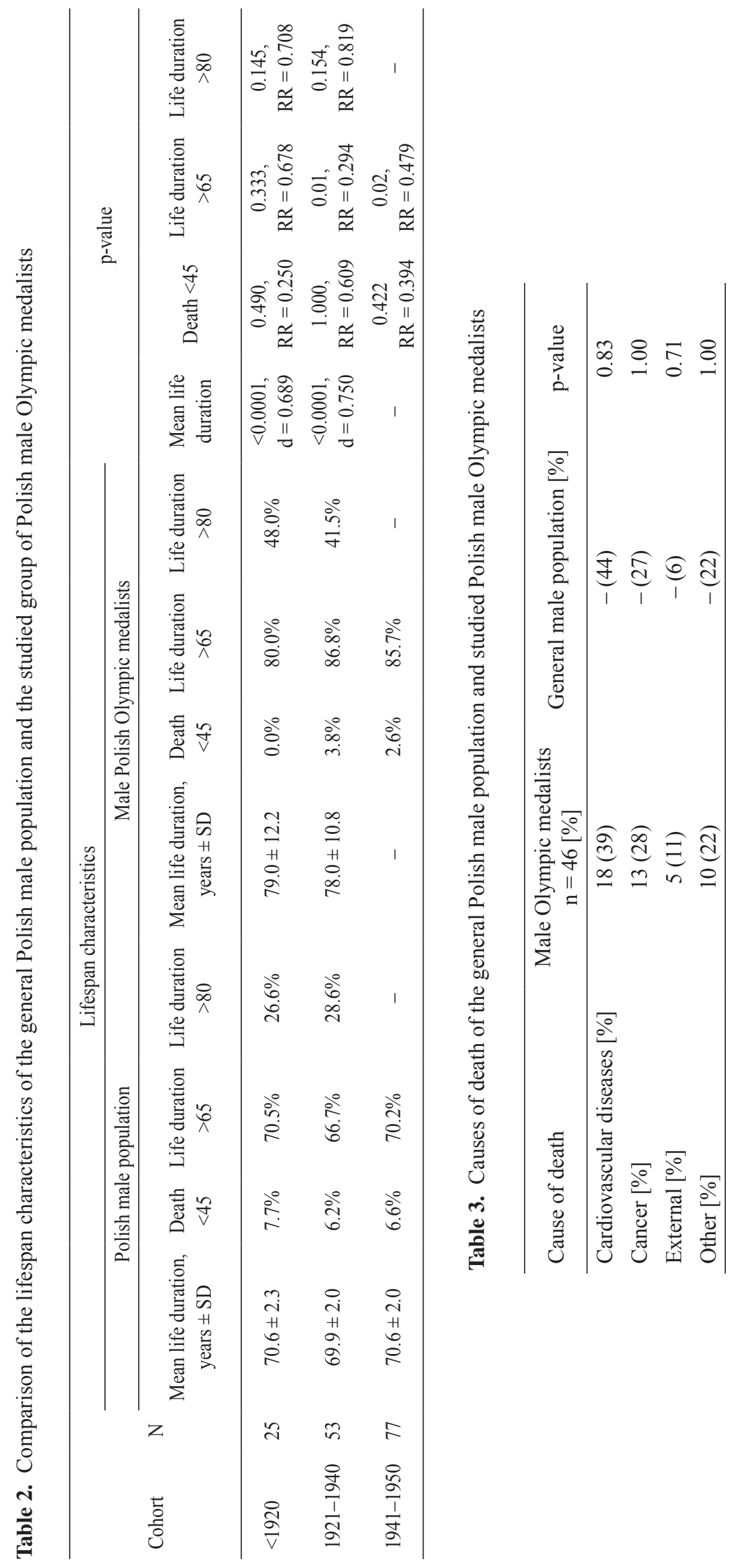



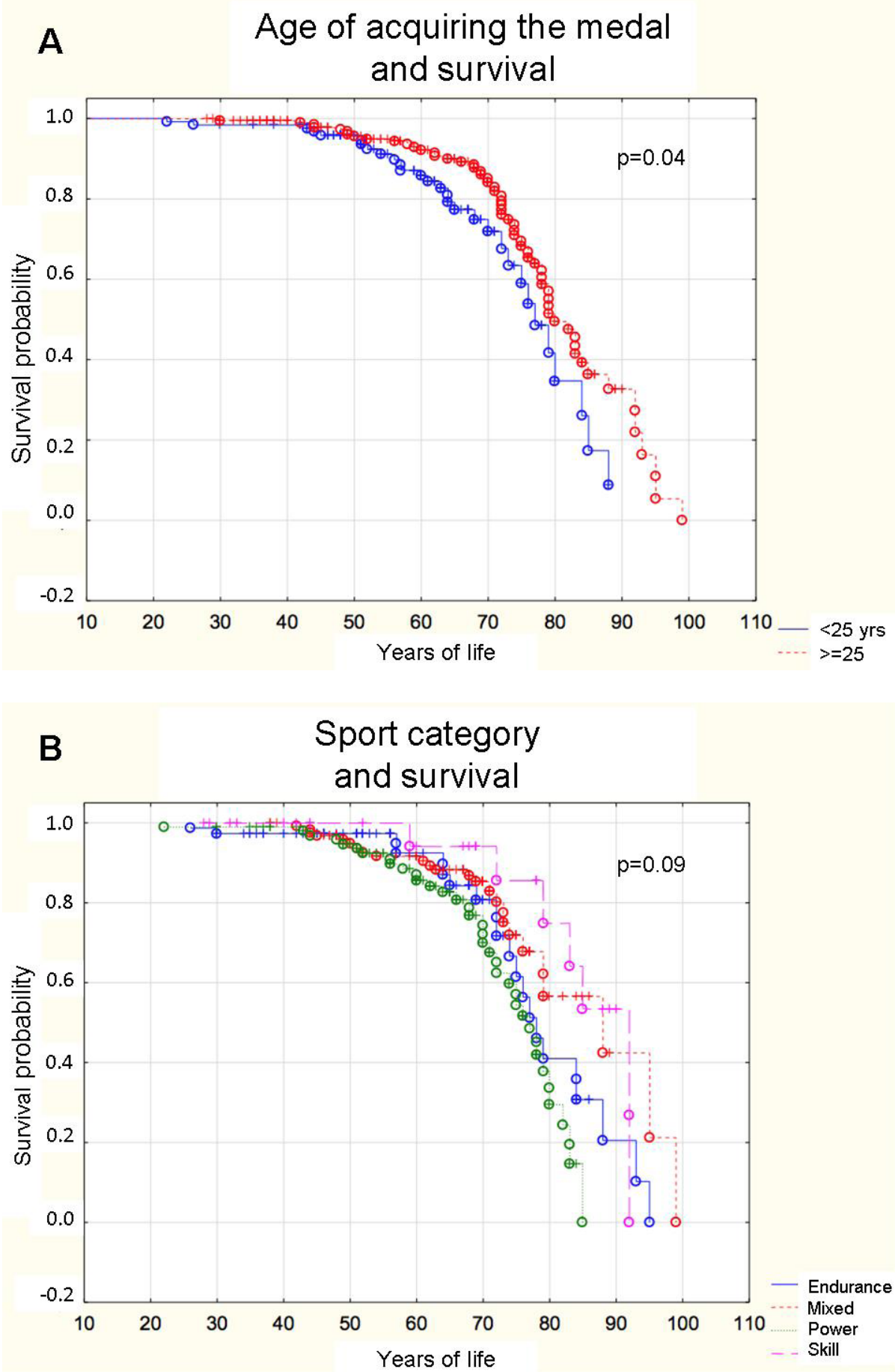

Figure 1. Kaplan-Meier curves presenting survival in the studied group of the Olympic medallists in relation to: (A) age of acquiring of the first medal and (B) different sport categories

most active men in comparison to the general population. It might be due to their genetic predisposition; thus it is a possibility that once the strenuous exercise factor was eliminated from that group, their life expectancy would be even longer. Unfortunately, a prospective analysis of such kind is close to impossible. Unequivocally the lifespan of examined Polish athletes is not shorter than in the subset of the most active men, showing that the price of victory cannot be too high. Olympic medallists most certainly are genetically predisposed towards better physical fitness and a longer life, as if that were not the case, they would be unlikely to pursue a successful sports career. Factors other than the pure physical activity present before, during and after the course of their professional career such as their lifestyle and acquired social benefits might also affect their longevity. A study of Finish twins including 
athletes and their brothers, and therefore eliminating genetic factors, demonstrated that athletes lived on average 3 years longer, pointing towards physical activity and lifestyle, which was better in athletes, as key factors leading to longer survival [14].

For the first time we looked for factors related to longer survival of the Polish male Olympic medallists. We demonstrated that Olympic medallists from mixed or skill sports had better survival than those who were engaging in pure endurance or power disciplines. This is in line with a French study, which showed a larger number of years saved from cardiovascular causes among precision and intermittent sports [2]. We were unable to obtain the cause of death for the whole studied group; nevertheless, cardiovascular deaths were numerically lower in our sample. Our results are at odds with a larger analysis on Olympic medallists, which demonstrated that survival was favoured in endurance sports over mixed and power disciplines [3].

Lowest lifespan gain associated with power sports, as shown by all the studies, can be explained by a generally higher body mass and a different lifestyle, but also by presumably higher frequency of doping use and/or head injuries in some power sports such as boxing, with all its consequences $[2,3,16]$. Noted worse outcome of endurance sports in comparison to skill or mixed sports can be explained on the basis of the higher energy demand, inclusion of mainly one type of muscle type or one type of activity. Whereas, less straining or more poly-modal activities may be more beneficial, on the basis of their similarity to the physical activity recommendations for optimal reduction of the cardiovascular risk [16, 23].

Interestingly, we also demonstrated that a younger age of acquiring a medal is associated with shorter survival in comparison to winners at an older age. This does not seem to be related to a sport category and may be dependent on an earlier onset of the sports career, which could affect the normal physical development of these individuals [15]. Their career may also last longer and therefore put them at higher risk of sports related injuries and complications of those.

Similarly to some other studies, but not all, we did not observe a difference in the type of medal won, the number of medals won or the type of sport (individual vs. team) $[3,6]$. Our findings were limited in the subject of team sports by the fact that only the younger cohorts won medals, so the examined samples were small.

Our study has some limitations. Firstly, it was based on a relatively small sample, at least in comparison to the other study on Olympic medallists [3]. Nevertheless, the larger study did not include Poland in the analysis and therefore we addressed the scarcity of data. Due to a predominance of male medallists in the Polish sample we were unable to include a large enough group of women to allow for a statistically robust analysis. Additionally, we were unable to analyse other factors which could have affected survival of Olympic medallists, such as their life after finishing their sports career, including lifestyle, social or economic factors and their changes over time $[12,13]$. Finally, we focused only on publicly available information, which limited the number of analysed factors. Nonetheless, we believe that these limitations do not significantly impair the novelty of the results of our study. It is the first study analysing the longevity of Olympic medallists in Poland. It shows that sports performance at the highest level is generally safe and does not have a significant impact on longevity. These findings can be used in promotion of a sporting career as a potential life path for children and adolescents.

\section{Conclusion}

Polish male Olympic medallists lived on average 8 years longer than the general population of Polish men. The survival was lower in athletes who won a medal before 25 years of age and in those who belong to endurance or power sport categories, in contrast to older aged winners or those engaging in skill or mixed sports categories. The type and number of medals won as well as the character of the sport (individual vs. team) did not seem to affect survival.

\section{Conflict of interest: Authors state no conflict of interest.}

\section{References}

1. Antero-Jacquemin J., Pohar-Perme M., Rey G., Toussaint J.F., Latouche A. (2018) The heart of the matter: years saved from cardiovascular and cancer deaths in an elite athlete cohort with over a century of follow-up. Eur. $J$. Epidemiol., 33: 531-543. DOI: 10.1007/s10654-0180401-0.

2. Antero-Jacquemin J., Rey G., Marc A., Dor F., Haïda A., Marck A., Berthelot G., Calmat A., Latouche A., Toussaint J.F. (2015) Mortality in female and male French Olympians: a 1948-2013 cohort study. Am. J. Sports. Med., 43: 1505-12. DOI: 10.1177/0363546515574691.

3. Clarke P.M., Walter S.J., Hayen A., Mallon W.J., Heijmans J., Studdert D.M. (2015) Survival of the fittest: retrospective cohort study of the longevity of Olympic medalists in the modern era. Br. J. Sports Med., 49: 898-902. DOI: 10.1136/bjsports-2015-e8308rep.

4. Clausen J.S.R., Marott J.L., Holtermann A., Gyntelberg F., Jensen M.T. (2018) Midlife cardiorespiratory fitness and the long-term risk of mortality: 46 years of follow-up. J. Am. Coll. Cardiol., 72: 987-995. DOI: 10.1016/j.jacc.2018.06.045. 
5. D’Ascenzi F., Caselli S., Alvino F., Digiacinto B., Lemme E., Piepoli M., Pelliccia A. (2019) Cardiovascular risk profile in Olympic athletes: an unexpected and underestimated risk scenario. Br. J. Sports Med., 53: 37-42. DOI: 10.1136/bjsports-2018-099530.

6. DiFiori J.P., Benjamin H.J., Brenner J.S., Gregory A., Jayanthi N., Landry G.L., Luke A. (2014) Overuse injuries and burnout in youth sports: a position statement from the American Medical Society for Sports Medicine. Br. J. Sports Med., 48: 287-8. DOI: 10.1136/bjsports2013-093299.

7. Eijsvogels T.M., Molossi S., Lee D.C., Emery M.S., Thompson P.D. (2016) Exercise at the extremes: the amount of exercise to reduce cardiovascular events. J. Am. Coll. Cardiol., 67: 316-329. DOI: 10.1016/j. jacc.2015.11.034.

8. Elliott A.D., Linz D., Mishima R., Kadhim K., Gallagher C., Middeldorp M.E., Verdicchio C.V., Hendriks J.M.L., Lau D.H., La Gerche A., Sanders P. (2020) Association between physical activity and risk of incident arrhythmias in 402406 individuals: evidence from the UK biobank cohort. Eur. Heart J., 41: 1479-1486. DOI: 10.1093/eurheartj/ehz897.

9. Garatachea N., Santos-Lozano A., Sanchis-Gomar F., Fiuza-Luces C., Pareja-Galeano H., Emanuele E., Lucia A. (2014) Elite athletes live longer than the general population: a meta-analysis. Mayo Clin. Proc., 89: 1195-1200. DOI: 10.1016/j.mayocp.2014.06.004.

10. Gaudreault V., Tizon-Marcos H., Poirier P., Pibarot P., Gilbert P., Amyot M., Rodés-Cabau J., Després J.P., Bertrand O., Larose E. (2013) Transient myocardial tissue and function changes during a marathon in less fit marathon runners. Can. J. Cardiol., 29: 1269-1276. DOI: 10.1016/j.cjca.2013.04.022.

11. Kettunen J.A., Kujala U.M., Kaprio J., Bäckmand H., Peltonen M., Eriksson J.G., Sarna S. (2015) All-cause and disease-specific mortality among male, former elite athletes: an average 50-year follow-up. Br. J. Sports Med., 49: 893-897. DOI: 10.1136/bjsports-2013-093347.

12. Kołodziej H., Lopuszańska M., Jankowska E.A. (2007) Decrease in sex difference in premature mortality during system transformation in Poland. J. Biosoc. Sci., 40: 297-312. DOI: 10.1017/S0021932007002453.

13. Kołodziej H,. Lopuszańska M., Bielicki T., Jankowska E.A. (2008) Social inequality in premature mortality among Polish urban adults during economic transition. Am. J. Hum. Biol., 19: 878-885. DOI: 10.1002/ajhb.20665.

14. Kontro T.K., Sarna S., Kaprio J., Kujala U.M. (2018) Mortality and health-related habits in 900 Finnish former elite athletes and their brothers. Br. J. Sports Med., 52: 89-95. DOI: $10.1136 /$ bjsports-2017-098206.

15. Leive A. (2018) Dying to win? Olympic Gold medals and longevity. J. Health Econ., 61: 193-204. DOI: 10.1016/j. jhealeco.2018.07.005.
16. Lemez S., Baker J. (2015) Do elite athletes live longer? A systematic review of mortality and longevity in elite athletes. Sports Med. Open., 1: 16. DOI: 10.1186/s40798015-0024-X.

17. Li X., Cui S., Xuan D., Xuan C., Xu D. (2018) Atrial fibrillation in athletes and general population: A systematic review and meta-analysis. Medicine (Baltimore), 97: e13405.

18. Li Y., Pan A., Wang D.D., Liu X., Dhana K., Franco O.H., Kaptoge S., Di Angelantonio E., Stampfer M., Willett W.C., Hu F.B. (2018) Impact of healthy lifestyle factors on life expectancies in the US population. Circulation, 138: 345-355. DOI: 10.1161/ CIRCULATIONAHA.117.032047.

19. Małek Ł.A., Bucciarelli-Ducci C. (2020) Myocardial fibrosis in athletes - current perspective. Clin. Cardiol., 43: 882-888. DOI: 10.1002/clc.23360.

20. Małek Ł.A., Czajkowska A., Mróz K., Witek K., Nowicki D., Postuła M. (2020) Factors related to cardiac troponin $\mathrm{T}$ increase after participation in a $100 \mathrm{Km}$ ultramarathon. Diagnostics (Basel), 10: 167. DOI: 10.3390/ diagnostics 10030167.

21. Mandsager K., Harb S., Cremer P., Phelan D., Nissen S.E., Jaber W. (2018) Association of cardiorespiratory fitness with long-term mortality among adults undergoing exercise treadmill testing. JAMA Netw. Open., 1: e183605. DOI: 10.1001/jamanetworkopen.2018.3605.

22. Merghani A., Maestrini V., Rosmini S., Cox A.T., Dhutia H., Bastiaenan R., David S., Yeo T.J., Narain R., Malhotra A., Papadakis M., Wilson M.G., Tome M., AlFakih K., Moon J.C., Sharma S. (2017) Prevalence of subclinical coronary artery disease in masters endurance athletes with a low atherosclerotic risk profile. Circulation, 136: 126-137. DOI: 10.1161/ CIRCULATIONAHA.116.026964.

23. Merghani A., Malhotra A., Sharma S. (2016) The Ushaped relationship between exercise and cardiac morbidity. Trends in Cardiovasc. Med., 26: 232-240. DOI: 10.1016/j.tcm.2015.06.005.

24. O’Keefe J.H., Franklin B., Lavie C.J. (2014) Exercising for health and longevity vs. peak performance: different regimens for different goals. Mayo Clin. Proc., 89: 1171-1175. DOI: 10.1016/j.mayocp.2014.07.007.

25. Pelliccia A., Adami P.E., Quattrini F., Squeo M.R., Caselli S., Verdile L., Maestrini V., Di Paolo F., Pisicchio C., Ciardo R., Spataro A. (2017) Are Olympic athletes free from cardiovascular diseases? Systematic investigation in 2352 participants from Athens 2004 to Sochi 2014. Br. J. Sports Med., 51: 238-243. DOI: 10.1136/bjsports2016-096961.

26. Salvagno G.L., Schena F., Gelati M., Danese E., Cervellin G., Guidi G.C., Lippi G. (2014) The concentration of high-sensitivity troponin I, galectin-3 and NT-proBNP substantially increase after a $60-\mathrm{km}$ ultramarathon. Clin. 
Chem. Lab. Med., 52: 267-272. DOI: 10.1515/cclm2013-0601.

27. Saravia S.G., Knebel F., Schroeckh S., Ziebig R., Lun A., Weimann A., Haberland A., Borges A.C., Schimke I. (2010) Cardiac troponin T release and inflammation demonstrated in marathon runners. Clin. Lab., 56: 51-58.

28. Schnohr P., O'Keefe J.H., Marott J.L., Lange P., Jensen G.B. (2015) Dose of jogging and long-term mortality. J. Am. Coll. Cardiol., 65: 411-9. DOI: 10.1016/j. jacc.2014.11.023.

29. Wen C.P., Wai J.P.M., Tsai M.K., Yang Y.C., Cheng T.Y., Lee M.C., Chan H.T., Tsao C.K., Tsai S.P., Wu X. (2011)
Minimum amount of physical activity for reduced mortality and extended life expectancy: a prospective cohort study. Lancet, 378: 1244-53. DOI: 10.1016/S0140-6736(11)60749-6.

\section{Received 10.08.2020 \\ Accepted 21.10.2020}

(C) University of Physical Education, Warsaw, Poland 